\title{
A SAÚdE E O MEIO AMBIENTE
}

Relação de condições de saneamento habitacional e parasitoses

\author{
Shih Ken (**)
}

\section{INTRODUÇAOO}

"A casa de uma pessoa que era seu castelo; o que equivale a dizer que tudo o que passava dentro dos limites da dasa era da incumbência exclusiva do proprietário e nada fora devia interferir" (6).

Esse pensamento individualista vem sendo modificado através dos tempos e hoje falamos em segurança e conservação de todo o meio ambiente, que é de responsabilidade dos organismos públicos e também de cada cidadão.

Dentre os problemas ambientais destacam-se aquêles relacionados com a habitação. Sabemos que existe relação direta e especifica entre casa e saúde, pois, a simples observação nos ensina que aquêles indivíduos, que habitam vivendas em condições de saneamento inadequadas, estão mais sujeitos a adquirirem enfermidades (6).

\section{OBJETIVO DESTE TRABALHO}

Inicialmente a nossa intenção era associar más condições de saneamento habitacional com doença. Mas, em vista da limitação do número de palavras imposta pelo concurso, vamos tentar determinar objetivamente, apenas qual a relação entre más condições de saneamento habitacional e parasitoses.

Este trabalho é baseado em pesquisa realizada no Hospital das Clínicas da FM da USP.

Abordaremos aspectos relacionados ao saneamento da água, esgôto e lixo, uma vez que êsses fatores podem tornar-se um perigo na transmissão de parasitoses.

(*) 2.0 premio no consurso instituldo pelo Departamento de Enfermagem da Winthrop S. A., em 1970.

(**) Aluna do Curso de Graduaçăo em Enfermagem. 
O questionário apresentado (anexo 1) está de acôrdo com o objetivo inicial e contem algumas perguntas cujas respostas não foram utilizadas no presente trabalho.

\section{DEFINIÇAO DE TERMOS}

Saneamento - "é o contrôle de todos os fatôres do meio físico do homem, que exercem ou podem exercer efeito deletério sôbre seu bem estar físico. mental e social" (10).

Parasitoses - "são doenças ocasionadas pelas diferentes espécies de parasitas que infestam o homem e os animais" (5). Interessam-nos os Protozoários (Giardíase), os Vermes (Ancilostomíase, Esquistossomose mansônica, Ascaridiase, Teníase, Estrongiloidíase, Oxiríase e Tricocefalíase).

Agua de boa qualidade - é aquela fornecida pelos sistemas públicos de abastecimento de água, que preenche os padrões de potabilidade físico-químico e bacteriológico (11).

Agua de má qualidade - é aquela oriunda do lençol freático (poço, fonte), ou de superfície (rio, lago), ou do armazenamento da água de chuva (cisternas). Essas águas poderiam ser de boa qualidade se tomadas certas precauções de proteção do manancial, captação e reservação adequada e um posterior tratamento domiciliar (11).

Destino adequado nos dejetos - é o afastamento conveniente dos dejetos de mođo que êstes não sejam acessíveis ao homem e aos vetores animados; não poluam a água e o solo; não acarretam mau odor e mau aspecto. Este afastamento é feito pela rêde de esgôto, e pela fossa não negra (fossa sêca e tamque séptico). Fossa sêca consiste em uma escavação no solo de profundidade tal que não contamine o lençol freático (em média, deve ter uma distância mínima de um metro e meio acima do lençol freático) e que seja protegida por um abrigo. Tanque séptico - é um tanque de sedimentação e digestão dos dejetos, do qual resulta um afluente líquido que será infiltrado no poço absorvente (11).

Destino adequado do lixo - é o método que evita a presença de vetores animados e a possibilidade de transmissão de doenças. Os métodos recomendados são: remoção pela limpeza pública, enterramento e incineração (11).

\section{MATERIAL E MÉTODO}

Devido a limitações de ordem material e de tempo consideramos a nossa população os pacientes internados no Hospital das Clínicas da FM da USP que, de modo geral, são os menos privilegiados quanto à assistência médica, pois não pođem usufruir dos Institutos de Previdência Social nem de hospitais particulares. 
Essa população foi estudada por meio de uma amostra obtida pelo método de amostragem de estágio duplo, isto é, na primeira etapa selecionamos os conglomerados (clínicas), e, na segunda etapa. foram selecionadas as unidades amostrais (pacientes), por amostragem casual simples, tendo sido usado como sistema de referência a lista de nomes dos pacientes.

tão

Clínicas consideradas: três clínicas Médicas, três clínicas Cirúrgicas, C. Urológica, C. Obstétrica, C. Ginecológica, C. Oftalmológica, C. Otorrinolanrigológica. Não foi possível incluir as clínicas: Pediátrica. Dermatológica, de Moléstias Infecto-Contagiosas, de Pronto-Socorro e Neurológica, por dificuldades na ooleta de dados, em vista das condições dos pacientes.

$O$ universo da pesquisa consta de 400 (quatrocentos) pacientes, maiores de doze anos, sendo a amostra de 80 (oitenta) pacientes $(20 \%)$.

O método para coleta de dados fol o de questionária preenchido em entrevista pessoal. Uma vez formulado o questionário, submetêmo-la a um teste piloto, após o qual ofram feitas as devidas modi licações (anexo I).

Os critérios utilizados foram os seguintes:

1) as perguntas foram elaboradas levando-se em consideração o nível de instrução das pessoas que geralmente procuram êsse hospital. Por isso foram incluidas apenas perguntas sobbre as doenças mais conhecidas, como resfriado, pneumonia, parasitoses, diarréia e bronquite;

2) quanto à parasitose, além das informaçōes do paciente, verificamos os exames parasitológicos de fezes, quando existiam;

3) os ftens do questionário referentes à localização e material de construção da casa foram colocados para serem relacionados com doenças respiratórias, e os relativos ao número de cômodos e ao número de pessoas, com o índice de confinamento;

4) consideramos apenas o paciente $\mathrm{e}$ as informaçōes sôbre sua casa, excluindo sua familia; isto devido à dificuldade de nos encontrarmos com os seus familiares;

5) quando o paciente sorteado estava impossibilitado de responder às perguntas ou ausente da clínica, tomamos o paciente cujo número do leito era imediatamente posterior ao dêle.

As entrevistas foram satisfatórias, não havendo recusa. A apuração e a tabulaçãa dos dados foram feitos manualmente. 
Adotamos como método de análise estatística os testes de associação em tabelas de contingência. Os testes foram realizados ao nível de significância de 5\%. Formulamos dois tipos de hipóteses:

H0 - hipótese de independência

H1 - hipótese de assaciação entre as duas variáveis em ques-

Pelo mesmo motivo anteriormente citado, sôbre o concurso, apresentamos somente alguns resultados que consideramos mais significativos.

\section{ANALISE DOS RESULTADOS (Anexo II)}

\section{1) Agua}

Pela tabela 1, verificamos que das 80 pessoas entrevistadas 64 $(80 \%)$ apresentavam parasitose intestinal.

Segundo a tabela 2,52 pessoas $(65 \%)$ não dispunham de água proveniente do abastecimento público e, destas, 35 (43,8\%) utilizavam-se de água de poço.

Segundo o método estabelecido, formulamos duas hipóteses a partir dos dados da tabela 3. Assim, temos:

Ho - parasitose não está relacionada com o tipço de água

H1 - parasitose está relacionada com o tipo de água.

$\mathrm{O}$ teste de Ho contra H1 fol feito através do cálculo de X2 e do coeficiente de associação de Yule. Observamos que:

$$
\begin{aligned}
& \mathbf{X} 2=5,51 \\
& \mathbf{X} 2=\text { valor oritico ao nível de significância } 5 \%=3,84
\end{aligned}
$$

Portanto, rejeitamos Ho, ou seja, há uma associação entre água de má qualidade e parasitose. Além disso, o coeficiente de Yule nos revela que a associação é quase perfeitamente negativa e sua magnitude é da ordem de 0,96 .

De acôrdo com os dados da tabela 4, verificamos que:

$\mathrm{X2}=3,32$ para um grau de liberdade

$$
\mathrm{X} 2=\text { crltico igual a } 3,84 \quad \mathrm{Y} \text { igual a }-\mathbf{0 , 7 5} \text {. }
$$

Disso resulta que não há associação entre as duas variáveis em questão. No entanto, não podemos dar crédito a êsse fato, pelo menos nêste trabalho. Uma série de outras variáveis atuariam simultâ- 
neamente, tais como: eficiência dos filtros utilizados, destino finai dos dejetos e do lixo, hábitos de higiêne, etc. Outros estudos, levando em consideração estas variáveis, poderão talvez, esclarecer essa ocorrência.

\section{2) Esgôto}

Pela tabela 5 constatamos que 59 pessoas $(73,7 \%)$ não residiam em casas servidas por rêde de esgóto e, destas, $30(37,5 \%)$ faziam uso de fossa negra.

A partir dos dados da tabela 6, aceitamos a hipótese de associação entre parasitose e destino inadequado dos dejetos (X2 observado igual a 6,02 para um grau de liberadade. X2 crítico igual a 3,84; $\mathrm{Y}$ igual $\mathrm{a}-0,97)$.

\section{3) Lixo}

Como podemos ver na tabela 7,42 pessoas $(52,5 \%)$ não tinham seu lixo recolhido pela Prefeitura e, destas, $35(43,7 \%)$ jogavam seu lixo na superfície da terra.

Pela análise estatística da tabela 8 , tomamos a decisão de aceltar a hipótese de que há associação entre parasitoses e destino inadequando do lixo ( $\mathrm{X} 2$ observado $=3,89$ e X2 crítico $=3,84$ ), Ressaltamos o fato de que o coeficiente de Yule é igual a - 1, significando que a associação é perfeita negativa.

\section{4) Verduras}

Pela tabela, podemos ver que 70 pessoas $(87,5 \%)$ lavavam as verduras sòmente em água e 10 pessoas $(12,5 \%)$ faziam uso das seguintes substâncias: vinagre, iodo, permanganato de potássio.

\section{CONCLUSOES}

Diante dos fatos apresentados podemos concluir que:

1) $5 \%$ da população estudada não gozava das vantagens da água proveniente do abastecimento público.

73,7\% da pcpulação não habitava em casa servida por rêde de esgôto e 52,5\% não tinha seu lixo recolhido pela Prefeitura.

Dêste modo podemos supor que os paclentes do hospital das Clínicas provêm de locais onde o saneamento do meio é precário.

2) Parece existir realmente associação entre água de má qualidade, destino inadequado do lixo, e dejetos com as parasitoses. 
3) Num país como o nosso, o saneamento é um problema de difícil solução devido às conđições sócio-econômicas. Há necessidade de uma contínua educação sanitária da população, para que se aproveite de seus próprios recursos, a fim de tornar suas condições de saneamento habitacional adequadas.

\section{SUGESTOEES}

Sendo o hospital uma organização de assistência à comunidade deve se preocupar com a saúde da mesma, não só no aspecto curativo como no preventivo, onde a educação sanitária dos pacientes é de fundamental importância.

Então, porque não incluir na rotina de admissão um pequeno questionário ou um método qualquer (conforme disponibilidade do hospital), que permita a levantamento das condiçōes de saneamento habitacional do paciente? $\mathbf{E}$, de acôrdo com o caso, seria dada a orientação necessária ou poderiam ser reunidos pequenos grupos de pacientes, aos quais seriam administradas aulas sôbre os seguintes itens:

\section{1) Agua}

Características de água de boa qualidade;

Transmissão de ddenças de veiculação hídrica e o perigo dessas doenças;

Medidas de proteção do manancial, captação e reservaçăo adequadas e o tratamento da água no domicílio;

2) Dejetos e lixo

Transmissão de doenças por meio das dejetos e do lixo, e o perigo dessas doenças;

Destino adequado dos dejetos e do lixono domićlio;

\section{3) Verduras}

Doenças adquridas por ingestão de verduras mal lavadas;

Maneira adequada de lavar as verduras de acôrdo com os recursos da familia.

Assim, um paciente orientado, tendo consciência dos seus problemas e dos meios adequados de melhorá-los, poderá transmitir seus conhecimentos à sua familia e desta para a comunidade.

Como a equipe de enfermagem é a que está mais tempo junto do paciente, o seu desempenho de atividades educativas deve ser eficiente e contínuo. 


\section{REFERENGIAS BIBLIOGRAFICAS}

ACKOFF, R. L. - Planejamento de pesquisa social. São Paulo, Herder 1967.

ASSOCIAÇAO AMERICANA DE SAƯdE PÚBLICA - Princípios básicos da habitação sadia. Rio de Janeiro, Serviço Nacional de Educação Sanitária, 1965.

BERQUO, E. - Bioestatística. São Paulo, Departamento deestatística da Faculdade de Saúde Pública da USP, 1968.

GOROMOSOV, M. S. - Base fisiologica de las normas sanitarias aplicables a la vivenda. Genebra, OMS, 1969.

GRANDE enciclopédia portuguêsa e brasileira. Rio de Janeiro, Ed. Enciclopédia, s.d.v. 20, p. 365.

HANLON, J. J. - Guias para la salud de la comunidad. México, La Prensa Médica Mexicana, 1967. p. 116-132.

MILANEZ, A. - A higiene da habitação. Rio de Janeiro, Victor, 1967.

MORAES, I. N. - Introdução à pesquisa cientffica. Revista do Hospital das Clínicas, 21: 248, 252, 1966.

NETTER, F. H. - The Ciba collectiom of medical illustratons: digestive system. New York, Ciba, 1962.

OLIVeira W. E. - Saneamento e o Programa Nacional de Habita§ão. São Paulo, Ed. da USP, 1966.

SAO PAULO. Universidade. Faculdade de Saúde Pública. - Apostilas de Saneamento. São Paulo, Faculdade de Saúde Pública da USP, 1970.

SILVA, M. J. N. D. - Sugestão para maior Integração da educação sanitária no curso de graduação em enfermagem. Revista da Escola de Enfermagem da USP, 2 (1): 39-60, 1968.

VERONESI, R. D. M. - Doenças infecciosas e parasitárias. 4." Ed. Rio de Janeiro, Guanabara Koogan, 1969. p. 3-19.

SHIH, Ken - A saúde e o meio ambiente: relação de condições de saneamento habitacional e parasitoses.

Rev. da Esc. de Enf. USP, 5(1): $81 \cdot 92-1971$. 


\section{ANEXO I}

\section{Questionário}

LEVANTAMENTO DE DADOS DE CONDIÇOES DE SANEAMENTO DOMICILIAR E DOENÇAS DOS PACIENTES INTERNADOS NO PREDIO CENTRAL DO HOSPITAL DAS CLINICAS.

Marque com $\mathrm{X}$ a resposta do paciente. $\mathrm{E}$ em caso de alguma observação, anotar.

\section{A - HABITAÇAO:}

1 - Sua casa é feita de:

a - tijolo..... b b madeira..... c c - outro.....

2 - Quantos cômodos tem? (cozinha e banheiro não contam)
$a-1 \ldots \ldots b \quad b-2 \ldots \ldots b \quad c-3 \ldots \ldots . d-4 \ldots \ldots$

$e-5 \ldots \ldots$

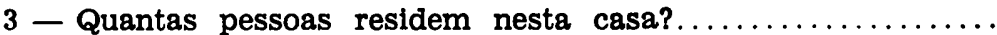

4 - Sua casa está no:

a - porão..... b - superfície.....

5 - Os cômodos recebem sol diretamente?

$a-\operatorname{sim} \ldots \ldots$ b - não.....

B - AGUA:

1 - Você usa água de:

a - rêde de abastecimento geral.......

b - poço comum......

c - lonte.......

d - superfície (rio, lago)...... 
e - outro

2 - E dado algum tratamento à água que se bebe? Qual? $a-$ não...... b - sim

\section{C - VERDURAS:}

1 - Você come verduras cruas?

$$
a-\operatorname{não} . \ldots . b \quad b-\operatorname{sim} \ldots \ldots .
$$

2 - Vocé lava as verduras com:

$$
\begin{aligned}
& a-\text { água...... b - água e sabão....... } \\
& c-\text { água e vinagre...... d - outra... }
\end{aligned}
$$

\section{D - ESGOTO:}

1 - $\mathrm{O}$ esgóto é lançado na:

a - réde de esgoto

$b$ - fossa - b1 - negra.

$$
\text { b2 - não negra....... }
$$

c - superfície da terra...... d - sargeta......

E - LIXO:

1-O lixo 6:

a - recolhido pelo serviço de limpeza pública.......

b - jogado na superffcie da terra.......

c - enterrado...... d - quelmado.......

e - outro.

F - DOENÇAS:

No perfodo de maio de 1969 a maio de 1970 , vocé teve:
a - resfriado
b - pneumonia.....
c - bronquite.......
d- diarrélas.......
e - parasitose...... 


\section{ANEXO II}

TABELA 1 - Paciente segundo a procedência da água destinada à alimentação e incidência de parasitose nos mesmos, Hospital das Clínicas, maio de 1970.

\begin{tabular}{l|r|r|r|r|r|r|r|r|r|r|r|r|r|r|r|r|r|r|r|}
\hline & Agua & \multicolumn{3}{|c|}{ Rêde } & \multicolumn{3}{|c|}{ Poço } & \multicolumn{3}{|c|}{ Fonte } & \multicolumn{2}{|c|}{ Superf. } & \multicolumn{2}{|c|}{ Cisterna } & TO. \\
\cline { 2 - 12 } & A & B & T & A & B & T & A & B & T & A & B & A & A & B & T & TAL \\
\hline Presente & 7 & 6 & 13 & 7 & 27 & 34 & 0 & 3 & 3 & 3 & 4 & 7 & 2 & 5 & 7 & 64 \\
Ausente & 12 & 3 & 15 & 0 & 1 & 1 & 0 & 0 & 0 & 0 & 0 & 0 & 0 & 0 & 0 & 16 \\
\hline Total & 19 & 9 & 28 & 7 & 28 & 35 & 0 & 3 & 3 & 3 & 4 & 7 & 2 & 5 & 7 & 80 \\
\hline
\end{tabular}

A - água tratada no domicílio (filtro ou fervura)

B - água não tratada no domicilio

T - subtotal

TABELA 2 - Distribuição dos pacientes do Hospital das Clínicas, maio de 1970, conforme a procedência da água destinaḍa à alimentação .

\begin{tabular}{l|c|c}
\hline \multicolumn{1}{c|}{ Procedência da água } & N.o pessoas & $\%$ \\
\hline Rêde de abastecimento & 28 & 35 \\
Poço & 35 & 43,8 \\
Fonte & 3 & 3,8 \\
Superfície & 7 & 8,7 \\
Cisterna & 7 & 8,7 \\
\hline
\end{tabular}

TABELA 3 - Pacientes segundo a qualdiade da água e a incidência de parasitose nos mesmos, Hospital das Clínicas, maio de 1970.

\begin{tabular}{|c|c|c|c|}
\hline Paras. Água & Boa qualidade & Má qualidade & $\therefore$ Total \\
\hline Presente & L3 & 51 & 64 \\
\hline Ausente & 15 & 1 & 16 \\
\hline Total & 28 & 52 & 80 \\
\hline
\end{tabular}


TABELA 4 - Pacientes segundo o tratamento domiciliar da água e a incidência de parasitose nos mesmos, Hospital das Clínicas, maio 1970.

\begin{tabular}{l|c|c|c}
\hline \hline Agua & Tratada & Não Tratada & Total \\
\hline Prasesente & 19 & 45 & 64 \\
Ausente & 12 & 4 & 16 \\
\hline Total & 31 & & 80 \\
\hline
\end{tabular}

TABELA 5 - Distribuição dos pacientes do Hospital das Clínicas, maio de 1970, conforme o destino final dos dejetos.

\begin{tabular}{l|c|c}
\hline \multicolumn{1}{c|}{ Destino dos objetos } & N.0 de pessoas & $\%$ \\
\hline \hline Rêde de esgôto & 21 & 26,3 \\
Fossa negra & 30 & 37,5 \\
Fossa não negra & 4 & 5,0 \\
Superf. terra & 14 & 17,5 \\
Sargeta & 11 & 13,7 \\
\hline
\end{tabular}

TABELA 6 - Pacientes segundo o destino final dos dejetos e incidência de parasitose nos mesmos, Hospital das Clínicas, maio de 1970.

\begin{tabular}{l|c|c|c}
\hline \multicolumn{1}{c|}{ Dest. Dejetos } & Adequado & Inadequado & Total \\
\hline Paras. & 10 & 54 & 64 \\
Presente & 15 & 1 & 16 \\
Ausente & 25 & 55 & 80 \\
\hline Total & \\
\hline \hline
\end{tabular}

TABELA 7 - Distribuição dos pacientes do Hospital das Clínicas, maio de 1970, conforme o destino final do lixo.

\begin{tabular}{l|c|c}
\hline \multicolumn{1}{c|}{ Destino do lixo } & N.o de pessoas & $\%$ \\
\hline \hline Prefeitura & 38 & 47,5 \\
Superf. terra & 35 & 43,7 \\
Enterrado & 1 & 1,3 \\
Queimado & 6 & 7,5 \\
\hline \hline
\end{tabular}


TABELA 8 - Pacientes conforme o destino final do lixo e incidência de parasitose nos mesmos, Haspital das Clínicas, maio de 1970.

\begin{tabular}{l|c|c|c}
\hline Dest. lixo & Adequado & Inadequado & Total \\
\hline Paras. & 29 & 34 & 64 \\
Presente & 16 & 0 & 16 \\
Ausente & 45 & 34 & 80 \\
\hline Total & 5 \\
\hline
\end{tabular}

TABELA 9 - Distribuição dos pacientes do Hospital das Clínicas, maio de 1970, conforme o modo de lavar as verduras.

\begin{tabular}{l|c|c}
\hline \hline Modo de lavar verduras & N.o de pessoas & $\%$ \\
\hline \hline Só água & 70 & 87,5 \\
Água com desinfetante & 10 & 12,5 \\
\hline
\end{tabular}

NOTA: Estas tabelas têm como fonte, os dadas obtidos do levantamento. 